Vol. 3, No. 2, 2018

\title{
IMPACT OF WEATHER FACTORS ON THE SPEED OF THE REACTION OF FORMALDEHYDE FORMATION ABOVE MOTORWAY OVERPASSES
}

\author{
Rostyslav Sipakov, Volodimir Trofimovich, Olena Voloshkina, Julia Bereznitska
}

\author{
Kyiv National University of Construction and Architecture, \\ 31, Vozduhoflotsky Av., Kyiv, 03680, Ukraine \\ e.voloshki@gmail.com
}

Received: 16.03 .2018

@ Sipakov R., Trofimovich V., Voloshkina O., Bereznitska J., 2018

\begin{abstract}
The analysis of the actual air condition in the city of Kyiv in the areas of big overpasses and crossroads shows that the average annual concentration of formaldehyde more than 3 times exceeds the maximum permissible concentration (MPC) of this toxic substance. One of the most powerful sources of formaldehyde formation in the air of the city is motor vehicles. The role of weather factors in formaldehyde formation rate $(\mathrm{K})$ depending on capacity of emissions of internal combustion engines has been analyzed in this article. The equation for determining rate constant has been obtained, which depends on the temperature in the city of Kyiv and on the value of effective energy activation of the mentioned process. The comparison of the calculated and measured values of the rate reaction constant in Observation Point (OP) No. 9 in the area of Leningradska square has been given. The conducted research gives the opportunity to assess and obtain forecasting data on atmospheric pollution and probability of smog situations emergence in Kyiv. The suggested methodology can be used for other cities in Ukraine where motor vehicles are the main indicator of photochemical smog emergence.
\end{abstract}

Key words: formaldehyde, indicator of pollution, impact of weather factors, motorway overpasses, concentration of pollution, mathematical model of atmospheric pollution

\section{Introduction}

The movable sources of pollution, in particular motor vehicles, currently play the main role in formation of air pollution index in big cities of Ukraine. According to the data from long-term observations of atmospheric air, the concentration of this extremely harmful impurity is constantly increasing. The studies of air pollution condition in big cities of Ukraine conducted by many authors $[4,12,13,19,21$ etc. $]$ have proven that along with quantity and intensity of pollution sources, weather conditions also play a very important role. As for the analysis of monitoring data of the city of Kyiv, the recent years data on air condition [23] show that formaldehyde as secondary pollutant and successor of hydrocarbon is changed quantitatively in a short period of time, that proves the fact that the sources of pollution with hydrocarbons are located uniformly in the area (methane - soils and water objects; isoprene vegetation; ethylene - transport system).

The aim of the research is to determine the impact of weather factors on the level of air pollution with formaldehyde in the city of Kyiv and to determine the kinetic component of pollution from the moving sources.

The object of the research is overpasses and big crossroads in Kyiv city, the subject of the research is the level of air pollution by formaldehyde in the areas with big concentration of vehicles.

The data from "National reports on the environment condition" during 2008-2014 as well as the observation materials given by Weather Prediction Center in Kyiv city were used as the output data.

\section{Results of research}

Monitoring of formaldehyde concentration in atmospheric air is being conducted at 12 observation posts. Although these posts are situated in different districts of the city, they are located near big motor crossroads and overpasses. Therefore, the use of the observation data from the posts was the starting point of the research. The research made by some authors [13] as well as the one made by us show that the dependence of formaldehyde concentration from temperature conditions in the air of a big city can be described by logarithmic dependencies.

Fig.1. shows the dependency $\mathrm{Cf}=\mathrm{F}\left(\mathrm{t}^{0}\right)$ on the example of observation posts (OP) No. 9 (Leningradska square). 


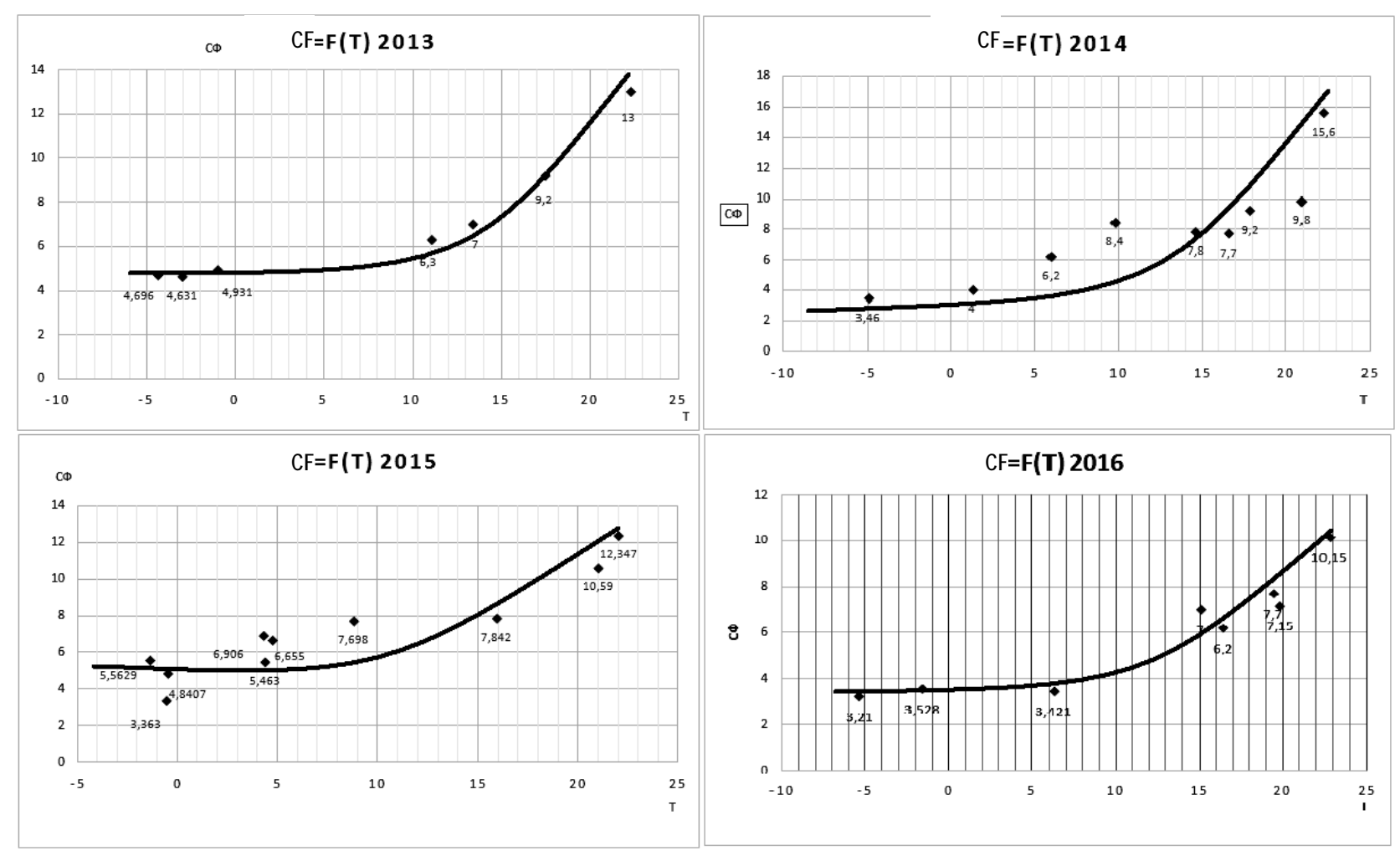

Fig. 1. Dependency $\mathrm{Cf}=\mathrm{F}\left(\mathrm{t}^{0}\right)$ on the example of the observation posts (OP) No. 9 (Leningradska square) during 2013-2016

The chart of consistency of averaged concentration of formaldehyde with weather factors and conditions in Kyiv city

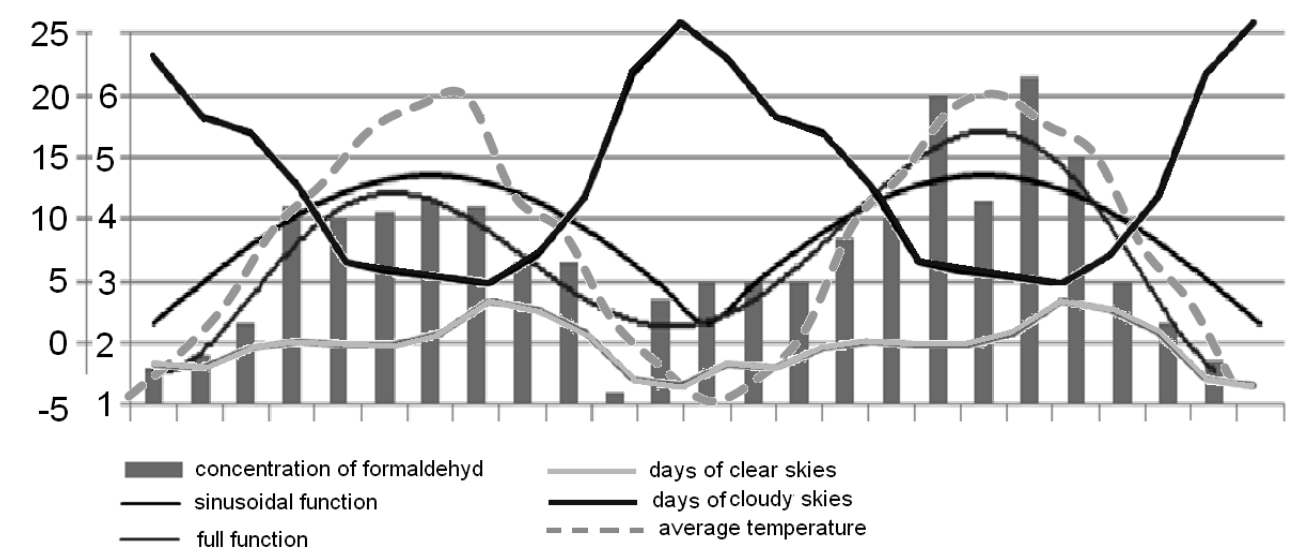

Fig. 2. Shows the chart of consistency of averaged concentration of formaldehyde

with weather factors and climate conditions in Kyiv according to the data of two-year observations in 2008-2009

Let's consider the process of formation of this harmful impurity in the air from mobile sources of pollution in detail.

In the surveys made by the authors [6, 14, 19 etc.], six main ways of transfer and transformation of emissions in the atmosphere have been distinguished.

I - sedimentation on weather conditions that are unstable according to air turbulence indicator and temperature distribution gradient according to the altitude

II - emission to the under-cloud washing by precipitation III - emission into clouds
IV - emission into the atmosphere in the open solar radiation.

$\mathrm{V}$ - rain fall from acid (polluted) clouds

VI - lifting of acid (polluted) clouds into the upper troposphere with transformation into drops.

Photochemical transformation of hydrocarbons $\left(\mathrm{C}_{\mathrm{x}} \mathrm{H}_{\mathrm{x}}\right)$ of different origin is described in detail in many works [6, 7, 16 etc.], for example, methane, hydrocarbon of biogenic origin - isoprene and alkenes are included into the emission of internal combustion engine. 
Attributing of emissions into the atmosphere to a particular structural component requires taking into account the factors of the given area, including climate, relief, soil and chemical ones. As for formaldehyde, probably, it can be considered as ozone or peroxyacetyl nitrate (PAN) if emissions are developing as in variant IV [6, 25].

Using classical methodology of correlation analysis which means the estimation of the level of dependence between the indicators, the authors have received coefficients of correlation connection between the air temperature and formaldehyde concentration that confirms the tight connection between these factors.

Background concentrations of $\mathrm{CHOH}$ are assumed to be formed by the constant factors such as soil $\left(\mathrm{CH}_{4}\right)$ and vegetation $\left(\mathrm{C}_{5} \mathrm{H}_{8}\right)$.

The presence of correlation connection between the concentrations of $\mathrm{CO}$ and $\mathrm{CHOH}$ in the air near big overpasses and crossroads [4] also confirms the presumption of many researchers that formaldehyde concentration in the air of Kyiv city can serve as an indicator of photochemical smog emergence in the areas of tense vehicles concentration.

According to the laws of chemical kinetics which are described particularly in the works [5, 6, 16 etc.] gas molecules can react only when they are coming close to each other for straight energy exchange, which can lead to breaking of the ties and rearrangement of atoms. As the collision of two molecules is a necessary condition of the reaction, there must be enough energy to break chemical connections. The reaction speed is determined by the formula that considers both frequency of collisions and the share of the required energy excess:

$$
\mathrm{K}=\mathrm{A}(\mathrm{T}) \cdot \exp (-\mathrm{E} / \mathrm{RT})
$$

where $\mathrm{K}$ is a a constant of the reaction speed, hour ${ }^{1}$; $\mathrm{T}$ - absolute temperature, $\mathrm{K} ; \mathrm{R}$ - universal gas constant, $\mathrm{J} /(\mathrm{mol} \cdot \mathrm{K})$; $\mathrm{E}-$ activation energy, the constant of the given reaction $\mathrm{J} / \mathrm{mol}$.

In the formula (1) the pre-exponential parameter $\mathrm{A}(\mathrm{T})$ characterizes the frequency of collision of the reacting molecules, so, it is considered to be the constant because of very slow dependence on the temperature (the assessment of the parameter in the temperature range from $200{ }^{\circ} \mathrm{C}$ to $300{ }^{\circ} \mathrm{C}$ leads to the change of collision A only by $10 \%$ ). Then the equation takes the form of Arrhenius equation [1]:

$$
\mathrm{K}=\mathrm{A} \cdot \exp (-\mathrm{E} / \mathrm{RT}) \text {. }
$$

According to [2] the dependence of the speed reaction constant from temperature in general is described by Vant-Hoff-Arrhenius differential equation, an integral solution of which has the form:

$$
\ln \mathrm{K}=-(\mathrm{E} / \mathrm{RT})+\mathrm{C} \text {, }
$$

where $\mathrm{C}$ is the integration constant.

Based on the monitoring observation data, the described equation allows to define effective energy of transformation process of $\mathrm{C}_{2} \mathrm{H}_{4}$ molecules into $\mathrm{CHOH}$ depending on weather conditions.

Fig. 3. presents the monitoring data in the coordinates $\ln \mathrm{K}-1 / \mathrm{T}$ for the transport hub in Leningradska Square (OP No. 9). With sufficient accuracy of calculations we accept $\ln \mathrm{K}=\ln \left(\mathrm{C}_{\mathrm{CHOH}} / \mathrm{C}_{\mathrm{CH}}\right)$, where the hydrocarbons concentration indicator from vehicles emission in the narrowest section of convective heat jet over the defined area was calculated according to the methodology described in the work [24].

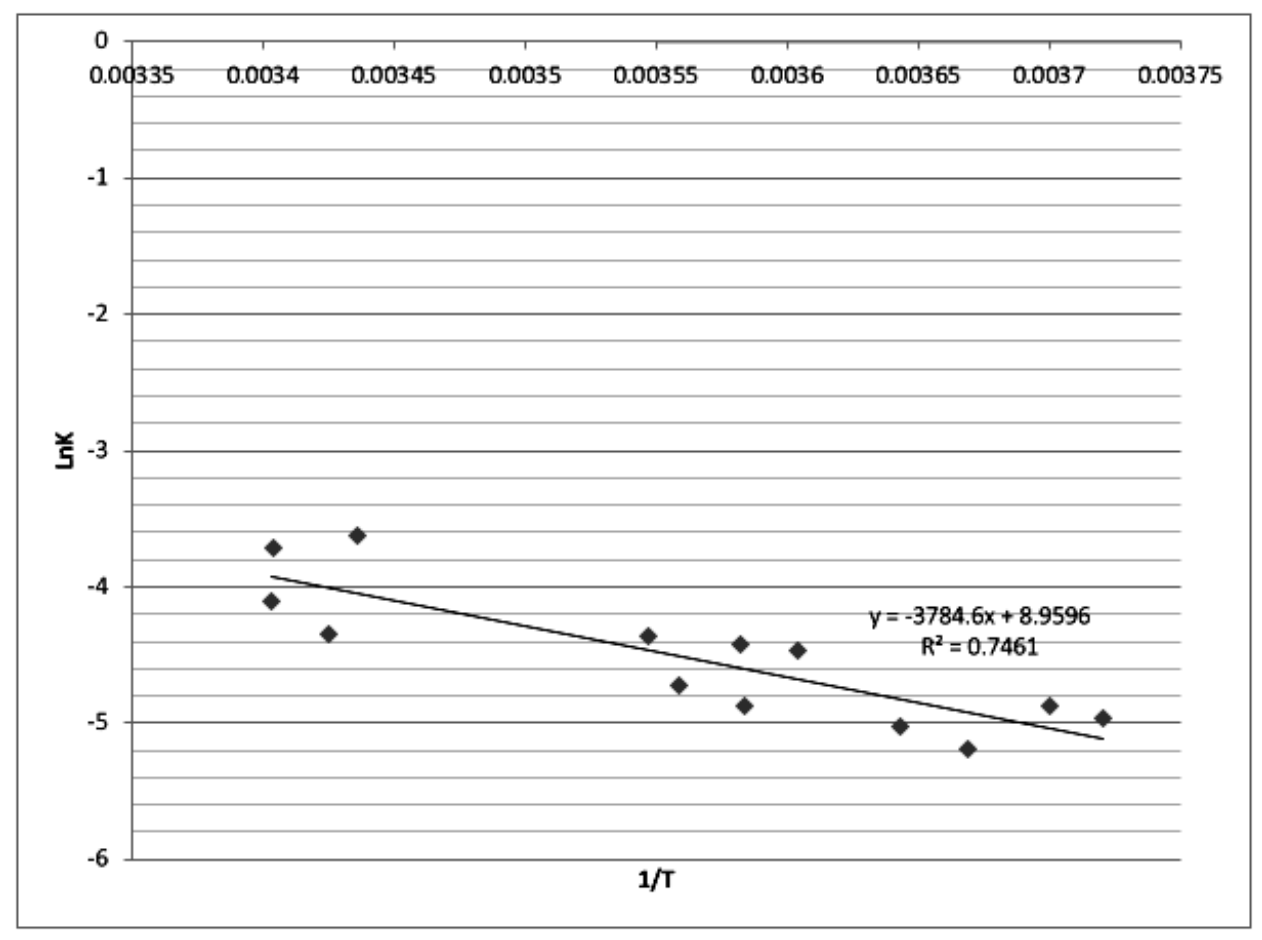

Fig. 3. Linear approximation of dependence $\ln \mathrm{K}=\mathrm{f}(1 / \mathrm{T})$ 
The data from Table 1 were used in calculations of the experimental points for the chart.

By standard means of linear regression we obtain the value of parameters $\mathrm{E}$ and $\mathrm{C}$.

Activation energy value

$\mathrm{E}=8.314 \cdot 3784.0=31460.176 \mathrm{KJ} / \mathrm{mol}$.
We obtain the average value of integration constant by the standard methodology (least-squares method) and determine the analytical form of dependence of speed constant $\mathrm{K}$ :

$$
\ln \mathrm{K}=\mathrm{C}-(\mathrm{E} / \mathrm{RT})=8.959-(3784 / \mathrm{T}),
$$

Table 2 presents the calculated values of speed constant $\mathrm{K}$; they are calculated considering the temperature $\mathrm{T}$.

\section{Hydrocarbon concentration from vehicles emission at OP № 9}

\begin{tabular}{|c|c|c|c|c|}
\hline OP & $\begin{array}{c}\text { The area of } \\
\text { thermal } \\
\text { surface, } \mathrm{m}^{2}\end{array}$ & $\begin{array}{c}\text { Heat from cars and } \\
\text { heat at the transport } \\
\text { hub (per month), } \\
\mathrm{MJ} / \mathrm{m}^{2}\end{array}$ & $\begin{array}{c}\text { Consumption in the } \\
\text { narrowest section } \\
\text { of convective heat } \\
\text { jet, } \mathrm{m}^{3} / \mathrm{s}\end{array}$ & $\begin{array}{c}\text { Concentration of emissions } \\
\text { from vehicles at the } \\
\text { distance of } 600 \mathrm{~m} \text { above } \\
\text { the surface, } \mathrm{mg} / \mathrm{m}^{3}\end{array}$ \\
\hline F. Leningradska Square & 61544 & 51635416 & 89222 & 0.5782 \\
\hline
\end{tabular}

Comparison of experimental and calculated values of speed constant of transformation of ethen emissions from vehicles into formaldehyde (OP №9, 2015-2016)

\begin{tabular}{|c|c|c|c|c|c|c|c|}
\hline $\mathrm{t}^{\circ} \mathrm{C}$ & $\mathrm{T}, \mathrm{K}$ & $(1 / \mathrm{T}) \cdot 10^{-4}$ & $\mathrm{~K}$ experiment & $\begin{array}{c}\ln \mathrm{K} \\
\text { experiment }\end{array}$ & lnK formula (2) & $\mathrm{K}$ formula (2) & $\Delta, \%$ \\
\hline 1 & 2 & 3 & 4 & 5 & 6 & 7 & 8 \\
\hline 4.3 & 277.76 & 36.04 & 0.00951 & -4.6565 & -4.6700 & 0.0094 & -0.1 \\
\hline 8.8 & 281.95 & 35.46 & 0.01193 & -4.4312 & -4.4500 & 0.0117 & -1.7 \\
\hline 15.9 & 289.1 & 34.59 & 0.01331 & -4.3192 & -4.1300 & 0.0161 & -17.4 \\
\hline 22.8 & 295.95 & 33.79 & 0.01747 & -4.0413 & -3.8270 & 0.0218 & +20.1 \\
\hline 31.4 & 304.53 & 32.83 & 0.02433 & -3.7292 & -3.4638 & 0.0314 & +22.75 \\
\hline 22.0 & 295.18 & 33.87 & 0.01644 & -4.1321 & -3.857 & 0.0211 & +22.27 \\
\hline 15.7 & 288.88 & 34.61 & 0.02127 & -3.8505 & -4.1374 & 0.0267 & +20.22 \\
\hline 4.7 & 277.89 & 35.98 & 0.01141 & -4.4733 & -4.655 & 0.0095 & +6.3 \\
\hline-1.4 & 271.76 & 36.68 & 0.00581 & -5.1482 & -4.663 & 0.0094 & +0.1 \\
\hline-0.5 & 272.65 & 36.67 & 0.0083 & -4.7915 & -4.917 & 0.0073 & -12.0 \\
\hline-5.3 & 268.19 & 36.72 & 0.00556 & -5.1922 & -5.151 & 0.0058 & +3.4 \\
\hline 1.71 & 274.86 & 36.36 & 0.0090 & -4.7105 & -4.799 & 0.0082 & -9.7 \\
\hline 5.7 & 278.83 & 35.86 & 0.0110 & -4.5099 & -4.610 & 0.0100 & -10.0 \\
\hline 12.9 & 286.05 & 34.96 & 0.0147 & -4.219 & -4.2698 & 0.0140 & -5.0 \\
\hline 15.0 & 288.25 & 34.69 & 0.0121 & -4.4156 & -4.2698 & 0.0140 & +14.2 \\
\hline 22.8 & 295.95 & 33.75 & 0.1747 & -4.0413 & -3.8270 & 0.0218 & +20.1 \\
\hline 19.5 & 292.61 & 34.17 & 0.0133 & -4.320 & -3.9709 & 0.0189 & +25.6 \\
\hline
\end{tabular}


As we can see from the data given in the Table, the possible error does not exceed $+25.6 \%$. This error can be explained by the following: the main process of smog emergence can occur at the altitude of $200 \mathrm{~m}$ and more and this fact is considered when making the experimental chart in Fig. 3 in calculation of quantities $\ln \left(\mathrm{C}_{\mathrm{CHOH}} / \mathrm{C}_{\mathrm{CH}}\right)$, when the monitoring measurements of quantities $\mathrm{C}_{\mathrm{CHOH}}$ occur in the surface layer of atmospheric air at the altitude about $2 \mathrm{~m}$ from the surface. Such positive error is variative, it tends to increase in summer months and occurs in many cities of Ukraine [19].

\section{Conclusions}

The seasonal and perennial nature of formaldehyde concentration is well agreed with the data of meteorological characteristics in the city of Kyiv. The analysis of long-term monitoring observations shows the tight correlation connection between temperature data at OP in Kyiv and formaldehyde concentration which can be described by logarithmic dependence.

The value of the constant of transformation speed of vehicles emission into formaldehyde which has been obtained using the suggested methodology when comparing the data of monitoring observations in Kyiv city, give the same value with the maximum errors mostly received in summer months, that can be explained by the frequency of smog emergence at the altitude of $2 / 3$ the diameter of the thermal dome which is formed above the overpass.

\section{References}

[1] Shtiller V. Arhenius equation and uneven kinetics. Moscow: Mir, 2000. - 176 p.

[2] [Theory of process of inorganic substance production / I. M. Astrelin, A. K. Zapolskiy, V. I. Suprunuk [and other]; by ed. A. K. Zapolskyi. - Kyiv, 1992. - 399 p.

[3] Vakal S. V., Scientific and theoretical basis on creation of new ecologically safe technological processes of phosphorus fertilizers production [Text]: abstract by Doctor of Engineering, 21.06.01 - ecological safety / S. V. Vakal. - Sumy: SumSU, 2018. -38 p.

[4] A. V. Chuhai. Atmospheric air pollution with specific pollutants in cities of the coastal zone of the northwestern Black sea coast / A. V. Chuhai, H. S. P atraman // Man and Environment. Problems of neo ecology. 2017. - No. 1-2(27). - P. 113-122.

[5] Aloyan A. E. Modeling of dynamics and kinetics of gas impurities and aerosols in the atmosphere. / Institute of Numerical Mathematics RAS. - M. : Nauka, 2008. - 415 p. (in translation.)
[6] John H. Seinfeld, Spiros N. Pandis / Atmospheric chemistry and physics / A Wiley-Interscience Publication, Printed in the USA, QC879.6. S45 1997. - 1356 p.

[7] Kenichi I., Toshiaki Y., Toshio T. Formaldehyde and acetaldehyde in exhaust gases emitted from an ethanolfueled S. I. engine // Bull. ISNE. - 1984. - Vol. 27, No. 227. - P. 945-951.

[8] Rate constant for gas phase reactions of nitrate with a series of organics in the air at $298 \_+1 \mathrm{~K} / \mathrm{R}$. Atkinson, C. N. Plum, W. P. L. Carter, et al. // J. Phys. Chem. 1984. - Yd88. - P. 1210-1215

[9] Pryschepov O. F., Levytska O. S. Peculiarities of the dispersion of harmful substances of airborne vehicle emissions in the city / Scientific works of the Petro Mohyla Black Sea State University. Sir Technogenic safety. - 2009. - 111, issue 98. - P. 139-146.

[10] Misliuk O. O., Shaikin O. Y. Assessment of ecological safety of motor transport operation in the conditions of an industrial city / Bulletin of ZHDTU No. 3 (46), 2008. P. 1-6.

[11] Skubnevskaya G. I., Dultseva G. G. Pollution of the atmosphere with formaldehyde: Analytical review / RAS. Sib otd. GPNTB, IKHK\&G. - Novosibirsk, 1994. $-70 \mathrm{~s}$.

[12] The level of atmospheric air pollution in Kyiv by formaldehyde / O. G. Shevchenko, M. I. Kulbida, S. I. Snizhko, L. S. Shcherbukha, N.O. Danilov // Ukrainian Hydrometeorological Journal, Odessa State Ecological University, 2014, No. 14, - P. 2-22.

[13] Polishchuk S. Z., Dotsenko L. V., Demidenko A. S. Estimation of the influence of meteorological factors on the state of atmospheric air pollution in the city of Dnipropetrovsk (on the example of formaldehyde) / Construction, materials science, machine building: Starodubsky Readings, 2015. - P. 266-270.

[14] Brigman, H. and Graham L,2003 "Air pollution and meteorology in a small city: the case study of Newcastle, NSW, Australia", Fifth International Conference on Urban Climate, University of Lods, Poland, September, 2003.

[15] Howard Brigman / Global air pollution, problems for the 1990s., CBS Publishers \& Distributors. - 1992. P. 261.

[16] Richard C. Flagan,John H. Seinfeld. Fundamentals of air pollution engineering / California Institute of Technology, 1988 by Prentice-Hall, Inc. A Division of Simon \& Schuster, Printed in the United States of America, 1988. - P. 542

[17] Aloyan A. E., Numerical modeling of the interaction of gas species and aerosol in the atmospheric dispersive system // Russ.J Num. Analysis Math. Modelling. 2000. - Vol. 15, No. 3-4. - P. 211-224.

[18] Formaldehyde pollution of the urban atmosphere and its dependence on meteorological factors / T. S. Selegay, N. N. Filonenko, V. A. Shlychkov, A. A. Lezhenin, T. N. Lenkovskaya // Optics of the Atmosphere and the Ocean, No. 25 (5), Novosibirsk. 2013. - P. 422-426. 
[19] Trofimovich V. V. Monitoring of atmospheric air. Problems of modeling and forecasting / V. V. Trofimovich, O. S. Voloshkina, M. M. Fandikova, I. V. Klimova, N. E. Zhuravska // Prob. Scientific works "Ecological safety and nature management", KNUBA, ITGIP NANU, K., 2012. - issue 10. - P. 102-120.

[20] Sheludenko L. S. Study of material balance "Fugitive emissions". Structure and volumes of harmful emissions, which are advanced by traffic flows // Collection of scientific works "Ecological safety and balanced resource-use", IFNTNUNG. - Ivano-Frankivsk, 2017. issue 2 (16). - 133-139 p.

[21] Methodology for calculation of pollutant emissions and carbon dioxide emissions from vehicles from the air / Approved by the State Statistics Committee of Ukraine on November 13, 2008, No. 452, Electronic resource access mode http: // ukrstat.org/.
[22] Snidzhko S. I. Urbometric aspects of atmospheric air pollution of a large city / S. I. Snizhko, O. G. Shevchenko. - K.: Publishing house geogr. litr. "Obriy", $2011-297$ p.

[23] Manual on the control of atmospheric pollution / M. E. Berlyand, G. I. Sidorenko. - L.: Gidrometeoizdat, 1979. - $448 \mathrm{p}$.

[24] Annual data of Central Meteorological Observatory in Kyiv for 2013-2016.

[25] Sipakov R.V Assessment and forecast for the creation of photochemical smog over transport overpasses in Kyiv / R. V. Sipakov, V. V. Trofimovich, O. S. Voloshkina, Y. O. Bereznitskaya // Prob. Scientific works "Ecological safety and nature management", KNUBA, ITGIP NANU, K., 2018. - issue 25. - P. 44-51

[26] Atmosphere protection from industrial pollutions: ed. S. Kalvert and G. M. Inglund. - M., 1988. - 760 p. 